\title{
Spontaneous bacterial peritonitis mortality trends of cirrhotic patients in the last decade in Constanta County
}

\author{
ROXANA-EMANUELA POPOIAG ${ }^{1}$, EUGENIA PANAITESCU ${ }^{2}$, ANDRA-IULIA SUCEVEANU ${ }^{3}$, \\ ADRIAN-PAUL SUCEVEANU ${ }^{3}$, SERGIU IOAN MICU $^{3}$, LAURA MAZILU $^{4}$, IRINEL PAREPA ${ }^{5^{*}}$, FELIX VOINEA ${ }^{6 *}$, \\ DANIEL OVIDIU COSTEA ${ }^{7}$, FLORIN ENACHE ${ }^{8}$ and CARMEN FIERBINȚEANU-BRATICEVICI $^{9}$ \\ ${ }^{1}$ Department of Internal Medicine 'Ovidius' University, Faculty of Medicine, 900527 Constanta; \\ ${ }^{2}$ Department of Informatics and Biostatistics, 'Carol Davila' University of Medicine and Pharmacy, 050474 Bucharest; \\ Departments of ${ }^{3}$ Internal Medicine, ${ }^{4}$ Oncology, ${ }^{5}$ Cardiology, ${ }^{6}$ Urology, ${ }^{7}$ Surgery and ${ }^{8}$ Pediatric Surgery, \\ Emergency Hospital, 'Ovidius' University, Faculty of Medicine, 900527 Constanta; ${ }^{9}$ Department of Gastroenterology, \\ University Hospital, 'Carol Davila' University of Medicine and Pharmacy, 050474 Bucharest, Romania
}

Received December 31, 2020; Accepted February 2, 2021

DOI: $10.3892 / \mathrm{etm} .2021 .10164$

\begin{abstract}
Spontaneous bacterial peritonitis (SBP) is a complication of liver cirrhosis with an increased in-hospital mortality rate. For this reason, the aim of the present study was to examine the main predictors of mortality in order to be able to identify high-risk patients in time and to guide the optimal treatment for prognosis improvement. We retrospectively collected demographic, clinical, laboratory and treatment data as well as data regarding length of stay and cost of hospitalization from 72 patients diagnosed with SBP between January 2010 and December 2019 in the Emergency Clinical Hospital St. Apostle Andrew, Constanta, Romania. Patients were divided into two groups: Those who survived and those who died. Logistic regression was used to identify a possible association between these factors and the increased risk of mortality. Univariate analysis revealed that clinical factors (fever, chills, and hepatic encephalopathy), biological factors such as serum and ascites leukocyte value, polymorphonuclear percentage (PMN), erythrocyte sedimentation rate (ESR) value, previous SBP episodes, and the presence of complications such as acute kidney injury (AKI), sepsis, and systemic inflammatory response syndrome (SIRS) were significantly associated with in-hospital mortality in patients with SBP. Multivariate analysis revealed that SIRS $(\mathrm{P}=0.0010)$ and fever $(\mathrm{P}=0.0258)$ were significantly associated with
\end{abstract}

Correspondence to: Professor Andra-Iulia Suceveanu, Department of Internal Medicine, Emergency Hospital, 'Ovidius' University, Faculty of Medicine, Bvd. Mamaia 124, 900527 Constanta, Romania E-mail: andrasuceveanu@yahoo.com

*Contributed equally

Key words: liver cirrhosis, spontaneous bacterial peritonitis, risk factors, mortality, sepsis in-hospital mortality in patients with SBP. Findings of the present study suggest that, SIRS and fever were independent predictive factors of mortality in cirrhotic patients with SBP.

\section{Introduction}

The mortality trend of liver cirrhosis during the period 1955-1990 underwent regional variations according to WHO data. Among the countries with the highest mortality rate were Chile and Mexico (60/100 000 men and 5/100 000 women) and at the opposite pole were Canada, the United States and the countries of South America (5-17/100,000 men, $3-5 / 100,000$ women). In the case of European countries, the United Kingdom, Ireland and the Nordic countries, the mortality rate was initially low but has shown a steady increase in recent years. A similar trend occurred in Eastern European countries in the early 1950s, thus, the highest mortality rate was recorded in Hungary $(57.5 / 100,000$ men and 22.0/100,000 women), Romania (34.8/100,000 men and 17.1/100,000 women), Czechoslovakia (31.9/100,000 men and 8.5/100,000 women) and the former Yugoslavia (22.6/100,000 men and 7.8/100,000 women) (1).

Although mortality has decreased in most countries in the world, in the United Kingdom and in the countries of Central and Eastern Europe there is still an upward trend due to the increasing prevalence of alcohol consumption (2). In the period 1970-2015, the countries of Southern and Western Europe recorded a low mortality rate, while the countries of Eastern and Northern Europe experienced a significant increase (3). Spontaneous bacterial peritonitis (SBP) is an infection that occurs in patients with cirrhosis and ascites, confirmed after excluding other possible causes of infections with in-hospital prevalence ranging from 10 to $30 \%$. Initially when it was first discovered, the mortality rate exceeded $90 \%$ but later had a downward trend with a current rate of $20 \%$ (4).

Early diagnosis is a challenge given the varied symptoms that SBP may have. Therefore, diagnostic paracentesis is recommended in all hospitalized patients with liver cirrhosis 
and ascites regardless of whether they show signs and symptoms of peritoneal infection (5). The positive diagnosis is based on a PMN value of $>250 \mathrm{~mm}^{3}$ in the ascites fluid. Positive culture is not required in the diagnosis of SBP but is useful in the administration of effective antibiotic treatment (6). It is known that kidney disease occurs frequently in patients with SBP and is a good predictor of mortality (7). Patients with SBP who have creatinine levels $\geq 2.0 \mathrm{mg} / \mathrm{dl}$ during treatment may be at increased risk of hospital mortality (8). Antibiotic-resistant bacteria are also an independent risk factor for mortality (9). In the present study, we aimed to investigate other risk factors associated with mortality in patients with SBP.

\section{Materials and methods}

Patients. This study was a retrospective, observational, and non-interventional. This study was approved by the local ethics committee no. 27/01.10.2020. The medical files of 72 patients (with a mean age of $59.29 \pm 11.2993,33.3 \%$ females and $66.7 \%$ males) with SBP and liver cirrhosis (surviving $\mathrm{n}=52$ and died $n=20$ ) of various etiologies hospitalized between January 2010 and December 2019 in the Emergency Clinical Hospital St. Apostle Andrew Constanta were studied. Patients aged $>18$ years, diagnosed according to European guideline criteria, i.e., a number of PMN $>250 \mathrm{~mm}^{3}$ in ascites fluid with or without positive culture (6). Patients with secondary causes of bacterial peritonitis (peritoneal carcinomatosis, pancreatitis, tuberculosis) by laboratory analysis and imaging investigations were excluded. Data regarding age, sex, etiology of liver cirrhosis, Child-Pugh score, symptomatology (fever, chills, abdominal pain, hepatic encephalopathy), laboratory findings (serum and ascites leukocytes, percentage of PMN in ascites fluid, ESR, serum sodium, and alkaline reserve), number of SBP episodes, complications (AKI, sepsis, SIRS), comorbidities, and ascites fluid culture were recorded.

The current study was approved by the Emergency Clinical Hospital St Apostle Andrew Constanta Ethics Committee, number 27/01.10.2020.

Statistical analysis. Data were analyzed using SPSS version 23. Numerical data were synthesized as mean \pm standard deviation or median and quartiles, and qualitative data were recorded as percentages. Data between the two groups were tested using the Pearson Chi-square test, Fisher's exact test and Mann-Whitney U test. Univariate logistic regression analysis was used to compare the two groups. Multivariate logistic regression analysis was performed to identify predictive factors of mortality. $\mathrm{P}<0.05$ was considered statistically significant.

Diagnosis of AKI was established by AKIN criteria (a sudden increase in serum creatinine within $48 \mathrm{~h} \geq 0.3 \mathrm{mg} / \mathrm{dl}$, a percentage increase in serum creatinine $\geq 50 \%$ or documented oliguria $<0.5 \mathrm{ml} / \mathrm{kg} / \mathrm{h}$ for $>6 \mathrm{~h}$ ) (10). Report criteria of the 7th meeting of the International Ascites Club were used to diagnose sepsis and SIRS (11).

\section{Results}

Patient characteristics. Patient characteristics were recorded by comparison between the groups of patients: Those who died and those who survived. Of the 72 patients diagnosed with SBP, 52 patients (72.2\%) had a favorable progression and 20 patients $(27.8 \%)$ died. In the group of patients who died, $35 \%$ were women and $65 \%$ were men, with a mean age of 59.5 years. Among the surviving patients $22.7 \%$ were women and $67.3 \%$ were men, with a mean age of 60 years.

The average duration of hospitalization in the surviving patients was 8.0 days and that of the patients who died was 9.50 days. The average cost of hospitalization was similar in the two groups: 3453 RON in surviving patients and 3651 RON in patients who died.

The proportion of patients who presented with a positive culture was $58.3 \%$. The most common isolated bacteria were Escherichia coli, Pseudomonas aeruginosa, and Enterococcus (33.3, 19.0 and $19.0 \%$, respectively), followed by Klebsiella $(16.7 \%)$. In 5 cases $(11.9 \%)$, Staphylococcus was identified, and in 3 cases $(7.1 \%)$, other microorganisms were identified (Table I).

Regarding treatment, most patients were treated with third-generation cephalosporin and quinolones (76.1 and $21.1 \%$, respectively). In 3 cases (4.2\%), vancomycin was administered, and in 2 cases (2.8\%) for other types of antibiotics (Table I).

No statistically significant differences were found between the two groups in terms of sex, age, length of stay, cost of hospitalization, culture of ascites fluid or treatment. Instead, statistically significant differences were found in the etiology of liver cirrhosis, Child-Pugh score, symptomatology, comorbidities and complications $(\mathrm{P}<0.05)$ (Table I).

A significantly higher proportion of patients who survived had the viral etiology $\mathrm{C}$ of liver cirrhosis than patients who died (38.5 vs. 10\%). Significant differences were recorded in the distribution of the Child Pugh score in deceased patients compared to survived patients in terms of class B and C: (0.0 vs. $36.5,0.0$ vs. $59.6 \%$ ). In addition, a significantly higher proportion of patients who died had fever (70 vs. $23.1 \%, \mathrm{P}<0.01$ ), chills (80 vs. $21.2 \%, \mathrm{P}<0.01$ ), and hepatic encephalopathy (55 vs. $26.9 \%, \mathrm{P}<0.01)$. Most patients who died had another episode of SBP ( 65 vs. $26.9 \%, \mathrm{P}<0.01$ ). Among the comorbidities, only the renal ones were found at a higher proportion of the patients who died than in those who survived (45 vs. $21.2 \%, \mathrm{P}=0.06$ ). Regarding metabolic complications, most patients presented dyslipidemia, obesity and sporadic increases in blood glucose without obvious evidence of diabetes (Table I).

The proportion of complications was significantly higher in patients who died than in those who survived, namely acute renal failure (65 vs. $21.2 \%, \mathrm{P}<0.01$ ), sepsis (40 vs. $1.9 \%$, $\mathrm{P}<0.01)$, and systemic inflammatory response syndrome $(75$ vs. 7.7\%, P<0.01) (Table I). Significant differences were found $(\mathrm{P}<0.05)$ in terms of laboratory findings and mortality. Patients who died had higher values of peripheral blood WBC (18.5 vs. 12.5, $\mathrm{P}=0.000825)$ and ESR (51.0 vs. 38.0, $\mathrm{P}=0.004098)$ but lower values of serum $\mathrm{Na}(115.0$ vs. $132.5, \mathrm{P}<0.01)$ and alkaline reserve $(12.0$ vs. $23.0, \mathrm{P}<0.01)$ than those who survived. In addition, the patients who survived had lower values of ascites leukocytes (542 vs. $2150, \mathrm{P}=0.012568$ ) and a lower percentage of PMN in ascites (71.1 vs. $89.8 \%, \mathrm{P}=0.002023)$ than those who died. The data are shown in Table II.

\section{Laboratory findings and mortality}

Univariate logistic regression analysis of risk factors associated with mortality in patients with SBP. Using univariate 
Table I. Characteristics of patients enrolled in the study based on mortality outcome.

\begin{tabular}{|c|c|c|c|c|}
\hline Category & Total $(n=72)$ & Died $(n=20)$ & Survived $(\mathrm{n}=52)$ & P-value \\
\hline Age $($ mean $\pm S D)$ & $\begin{array}{c}59.29 \pm 11.2993 \\
60.0(52.2-66.5)\end{array}$ & $59.5(53.2-64.0)$ & $60.0(52.0-68.5)$ & 0.830599 \\
\hline $\begin{array}{l}\text { Sex }[\mathrm{n}(\%)] \\
\text { Female } \\
\text { Male }\end{array}$ & $\begin{array}{l}24 / 72(33.3) \\
48 / 72(66.7)\end{array}$ & $\begin{array}{r}7 / 20(35.0) \\
13 / 20(65.0)\end{array}$ & $\begin{array}{l}17 / 52(32.7) \\
35 / 52(67.3)\end{array}$ & 0.852404 \\
\hline $\begin{array}{l}\text { Etiology [n (\%)] } \\
\text { Alcoholic } \\
\text { Viral B } \\
\text { Viral C } \\
\text { Others }\end{array}$ & $\begin{array}{c}44 / 72(61.1) \\
13 / 72(18.1) \\
22 / 72(30.6) \\
3 / 72(4.2)\end{array}$ & $\begin{array}{r}14 / 20(70.0) \\
2 / 20(10.0) \\
2 / 20(10.0) \\
2 / 20(10.0)\end{array}$ & $\begin{array}{c}30 / 52(57.7) \\
11 / 52(21.2) \\
20 / 52(38.5) \\
1 / 52(1.9)\end{array}$ & $\begin{array}{l}0.337297 \\
0.329728 \\
0.018862 \\
0.184777\end{array}$ \\
\hline $\begin{array}{l}\text { Child Pugh [n (\%)] } \\
\text { Grade A } \\
\text { Grade B } \\
\text { Grade C }\end{array}$ & $\begin{array}{c}2 / 72(2.8) \\
19 / 72(26.4) \\
51 / 72(70.8)\end{array}$ & $\begin{array}{r}0 / 20(0.0) \\
0 / 20(0.0) \\
20 / 20(0.0)\end{array}$ & $\begin{array}{c}2 / 52(3.8) \\
19 / 52(36.5) \\
31 / 52(59.6)\end{array}$ & 0.000228 \\
\hline $\begin{array}{l}\text { Symptomatology [n (\%)] } \\
\text { Fever } \\
\text { Chills } \\
\text { Abdominal pain } \\
\text { Hepatic encephalopathy }\end{array}$ & $\begin{array}{l}26 / 72(36.1) \\
27 / 72(37.5) \\
61 / 72(84.7) \\
25 / 72(34.7)\end{array}$ & $\begin{array}{l}14 / 20(70.0) \\
16 / 20(80.0) \\
19 / 20(95.0) \\
11 / 20(55.0)\end{array}$ & $\begin{array}{l}12 / 52(23.1) \\
11 / 52(21.2) \\
42 / 52(80.8) \\
14 / 52(26.9)\end{array}$ & $\begin{array}{l}0.000205 \\
0.000004 \\
0.184775 \\
0.000205\end{array}$ \\
\hline $\begin{array}{l}\text { SBP episodes }[\mathrm{n}(\%)] \\
0 \\
1 \\
2\end{array}$ & $\begin{array}{c}40 / 72(55.6) \\
27 / 72(37.5) \\
5 / 72(6.9)\end{array}$ & $\begin{array}{r}5 / 20(25.0) \\
13 / 20(65.0) \\
2 / 20(10.0)\end{array}$ & $\begin{array}{c}35 / 52(67.3) \\
14 / 52(26.9) \\
3 / 52(5.8)\end{array}$ & 0.004479 \\
\hline Comorbidities [n (\%)] & $53 / 72(73.6)$ & $17 / 20(85.0)$ & $36 / 52(69.2)$ & 0.173890 \\
\hline Pulmonary [n (\%)] & $11 / 72(15.3)$ & $2 / 20(10.0)$ & $9 / 52(17.3)$ & 0.716144 \\
\hline Cardiac $[\mathrm{n}(\%)]$ & $18 / 72(25.0)$ & $2 / 20(10.0)$ & $16 / 52(30.8)$ & 0.068314 \\
\hline Renal [n (\%)] & $20 / 72(2.8)$ & $9 / 20(45.0)$ & $11 / 52(21.2)$ & 0.068314 \\
\hline Metabolic [n (\%)] & $13 / 72(18.1)$ & $4 / 20(20.0)$ & $9 / 52(17.3)$ & 0.745657 \\
\hline Digestive $[\mathrm{n}(\%)]$ & $25 / 72(34.7)$ & $6 / 20(30.0)$ & $19 / 52(36.5)$ & 0.601696 \\
\hline $\begin{array}{l}\text { Complications [n (\%)] } \\
\text { AKI } \\
\text { Sepsis } \\
\text { SIRS }\end{array}$ & $\begin{array}{r}24 / 72(33.3) \\
9 / 72(66.7) \\
19 / 72(96.4)\end{array}$ & $\begin{array}{r}13 / 20(65.0) \\
8 / 20(40.0) \\
15 / 20(75.0)\end{array}$ & $\begin{array}{c}11 / 52(21.2) \\
1 / 52(1.9) \\
4 / 52(7.7)\end{array}$ & $<0.001$ \\
\hline $\operatorname{LOS}($ mean $\pm \mathrm{SD})$ & $\begin{array}{c}9.79 \pm 6.0814 \\
9.00(5.00-12.00)\end{array}$ & $9.50(7.00-12.50)$ & $8.0(5.00-12.00)$ & 0.26392 \\
\hline Total hospital charges $(\text { mean } \pm \mathrm{SD})^{\mathrm{a}}$ & $\begin{array}{c}3,986.5 \pm 2,786.46 \\
3,453(1,920-5,340)\end{array}$ & $3,651(2,357-6,353)$ & $3,453(1,676-4,828)$ & 0.164701 \\
\hline Positive culture [n (\%)] & $42 / 72(58.3)$ & $14 / 20(70.0)$ & $28 / 52(53.8)$ & 0.213022 \\
\hline Escherichia coli $[\mathrm{n}(\%)]$ & $14 / 42(33.3)$ & $3 / 14(21.4)$ & $11 / 28(39.3)$ & 0.313331 \\
\hline Pseudomonas aeruginosa [n (\%)] & $8 / 42(19.0)$ & $2 / 14(14.3)$ & $6 / 28(21.4)$ & 0.696909 \\
\hline Enterococcus [n (\%)] & $8 / 42(19.0)$ & $5 / 14(35.7)$ & $3 / 28(10.7)$ & 0.092357 \\
\hline Staphylococcus [n (\%)] & $5 / 42(11.9)$ & $3 / 14(21.4)$ & $2 / 28(7.1)$ & 0.312580 \\
\hline Klebsiella [n (\%)] & $7 / 42(16.7)$ & $0 / 14(0.0)$ & $7 / 28(25.0)$ & 0.075183 \\
\hline Others $[\mathrm{n}(\%)]$ & $3 / 42(7.1)$ & $2 / 14(14.3)$ & $1 / 28(3.6)$ & 0.253659 \\
\hline Days of treatment & $\begin{array}{c}6.69 \pm 2.3294 \\
7.00(5.00-7.00)\end{array}$ & $7.00(7.00-7.00)$ & $7.00(5.00-9.25)$ & 0.162567 \\
\hline \multicolumn{5}{|l|}{ Antibiotics [n (\%)] } \\
\hline Cephalosporins & $54 / 71(76.1)$ & $15 / 20(75.0)$ & $39 / 51(76.5)$ & 1.000000 \\
\hline Vancomycin & $3 / 71(4.2)$ & $2 / 20(10.0)$ & $1 / 51(2.0)$ & 0.189485 \\
\hline Quinolones & $15 / 71(21.1)$ & $3 / 20(15.0)$ & $12 / 51(23.5)$ & 0.531171 \\
\hline Others & $2 / 71(2.8)$ & $2 / 20(10.0)$ & $0 / 51(0.0)$ & 0.076459 \\
\hline
\end{tabular}

${ }^{a}$ Total hospital charges are expressed in the country's currency. SD, standard deviation; SBP, spontaneous bacterial peritonitis, AKI, acute kidney injury; SIRS, systemic inflammatory response syndrome; LOS, length of stay. 
Table II. Laboratory findings based on mortality outcome.

\begin{tabular}{lcccr}
\hline Category & Total $(\mathrm{n}=72)$ & Died $(\mathrm{n}=20)$ & Survived $(\mathrm{n}=52)$ & P-value \\
\hline Peripheral blood WBC $\left(10^{3} / \mu \mathrm{l}\right)$ & $14.41 \pm 7.0534$ & $18.5(14.9-27.5)$ & $12.5(8.8-15.2)$ & 0.000825 \\
& $13.1(10.0-17.7)$ & & & \\
ESR $(\mathrm{mm} / \mathrm{h})$ & $46.16 \pm 17.4195$ & $51.0(42.0-74.0)$ & $38.0(32.0-48.0)$ & 0.004098 \\
& $39.5(34.0-52.7)$ & & & \\
Ascites WBC $\left(/ \mathrm{mm}^{3}\right)$ & $1,646.6 \pm 2,169.9164$ & $2,150(383-5,050)$ & $542(317-1,079)$ & 0.012568 \\
& $629.0(346.2-2,152)$ & & & \\
\% PMN in ascites fluid & $74.23 \pm 18.1780 \%$ & $89.8 \%(79.1-94.5 \%)$ & $71.1 \%(51.2-87.3 \%)$ & 0.002023 \\
& $80.0 \%(57.2-88.9 \%)$ & & & $<0.001$ \\
Serum Na (mmol/l) & $128.05 \pm 9.9589$ & $115.0(110.2-118.0)$ & $132.5(129.0-138.0)$ & $<0.001$ \\
& $130.0(120.0-136.7)$ & & & \\
Alkaline reserve $(\mathrm{mmol} / \mathrm{l})$ & $19.85 \pm 6.0226$ & $12.0(10.0-15.0)$ & $23.0(19.2-25.0)$ & \\
\end{tabular}

Expressed as median (range). WBC, white blood cell; ESR, erythrocyte sedimentation rate; PMN, polymorphonuclear leukocyte; Na, sodium.

logistic regression analysis, the risk factors associated with mortality in patients with SBP were fever (OR 7.77, 95\% CI, 2.45-24.65), chills (OR 14.90, 95\% CI, 4.13-53.72), hepatic encephalopathy (OR 3.31, 95\% CI, 1.13-9.70), serum leukocytes (OR 1.16, 95\% CI, 11.06-1.27), ESR (OR 1.05, 95\% CI, 1.00-1.09), leukocytes in ascites fluid (OR 1.00, 95\% CI, 1.00-1.01), percentage of PMN in ascites fluid (OR 1.04, 95\% CI, 1.00-1.08), number of previous episodes of SBP (OR 3.27, 95\% CI, 1.36-7.83), presence of renal comorbidities (OR 3.05, 95\% CI, 1.01-9.19), acute renal failure (OR 6.92, 95\% CI, 2.22-21.52), sepsis (OR 34.00, 95\% CI, 3.87-298.34) and systemic inflammatory response syndrome (OR 36.00, 95\% CI, 8.55-151.48). The viral etiology of liver cirrhosis $\mathrm{C}$ in patients with SBP was an exception (Table III).

Multivariate analysis. Significant variables or close to the significance limit in the univariate analysis were introduced in the logistic regression analysis. Multivariate analysis identified two predictors of mortality in patients with hepatic cirrhosis and SBP (Table IV).

\section{Discussion}

In our study, in-hospital mortality in the period January 2010 and December 2019 was $27.8 \%$, which is similar to the value reported by Poca et al in a retrospective cohort study conducted in Barcelona, Spain, 2011-2001 (12). In their study, the mortality rate was $28 \%$ with the mention that only patients with SBP and increased risk of adverse events were included. This means that there has not been a descendant trend in mortality in the last decade despite the attempt of a prompt diagnosis and early appropriate treatment.

The univariate analysis of the present study revealed a statistically significant association between the presence of renal failure, hepatic encephalopathy and sepsis in patients with PBS and in-hospital mortality (65 vs. $21.2,55$ vs. 26.9, and 40 vs. $1.9 \%$ ). Additionally, Niu et al in a study conducted between 2006-2014 with an increased number of patients showing that a large proportion of patients who died had these risk factors compared to those who survived (72.4 vs. 35.3, 34.5 vs. 21.5 , and 68.4 vs. $22.6 \%$ ) (13).

In the study by Bal et al the value of serum leukocytes was significantly higher in patients who died than in those who survived $(15.17 \pm 9.82$ vs. $11.86 \pm 8.65)$. However, no differences were observed in the Child Pugh score between the two groups (14). In our study, there were differences in both variables (serum leukocyte value and Child Pugh score) between patients who died and survived. Specifically, the group of deceased patients showed also increased average value of serum leukocytes (8.5 with a range between 14.9 and 27.5) comparative with group of survived (12.5 with a range between 8.8 and 15.2). Regarding the Child Pugh score, all 20 patients who died $(0.0 \%)$ were in class $\mathrm{C}$ and only 31 patients were in this class in the surviving group (59.6\%). By contrast, the univariate analysis did not record it as a risk factor associated with mortality.

Previously, there has been a change in the epidemiology of microorganisms isolated in ascites fluid of patients with liver cirrhosis through an increase in infection with gram-positive cocci and multi-drug resistant bacteria (15). Staphylococcus infection is also associated with an increased risk of mortality in patients with SBP (16). In our study, Staphylococcus microorganisms were identified in five cases $(11.9 \%)$ and in three of these $(4.2 \%)$ they were methicillin-resistant and treated with vancomycin. Of these three cases, only one patient survived. Given the small number of patients, our study did not identify the type of microorganisms involved in the occurrence of SBP as a risk factor for mortality.

The results of the present study are similar to those recorded by Tsung et al (17) regarding the presence or absence of culture in ascites fluid and the type of microorganisms detected. These parameters did not affect the survival rate of patients with SBP. In their study, 39 patients from 95 (41.1\%) had a positive culture and the most common isolated bacteria was Escherichia coli (25.5\%). In their study, as in our study, patients with a Child Pugh score ${ }^{3} 10$ had a lower survival rate than patients with a Child Pugh score $<10(\mathrm{P}=0.019)(17)$. Instead compared to their study, we identified an association 
Table III. Univariate logistic regression analysis of risk factors associated with mortality in patients with SBP.

\begin{tabular}{|c|c|c|c|c|}
\hline Parameters & Coefficients & P-value & OR value & $95 \% \mathrm{CI}$ \\
\hline Fever & 0.000492 & 0.000205 & 7.77 & $2.45-24.65$ \\
\hline Chills & 0.000036 & 0.000004 & 14.90 & $4.13-53.72$ \\
\hline Hepatic encephalopathy & 0.028503 & 0.000205 & 3.31 & $1.13-9.70$ \\
\hline Peripheral blood WBC $\left(10^{3} \mu 1\right)$ & 0.000875 & 0.000825 & 1.16 & $11.06-1.27$ \\
\hline Ascites WBC $\left(/ \mathrm{mm}^{3}\right)$ & 0.008195 & 0.012568 & 1.00 & $1.00-1.01$ \\
\hline$\%$ PMN ascites & 0.014296 & 0.002023 & 1.04 & $1.00-1.08$ \\
\hline $\operatorname{ESR}(\mathrm{mm} / \mathrm{h})$ & 0.016362 & 0.004098 & 1.05 & $1.00-1.09$ \\
\hline Previous episodes of SBP & 0.007682 & 0.004479 & 3.27 & $1.36-7.83$ \\
\hline Renal comorbidities & 0.047773 & 0.068314 & 3.05 & $1.01-9.19$ \\
\hline AKI & 0.000831 & 0.000408 & 6.92 & $2.22-21.52$ \\
\hline Sepsis & 0.001461 & 0.000079 & 34.00 & $3.87-298.34$ \\
\hline SIRS & 0.000001 & $<0.001$ & 36.00 & $8.55-151.48$ \\
\hline Viral C etiology & 0.030431 & 0.018862 & 0.17 & $0.03-0.84$ \\
\hline
\end{tabular}

OR, odds ratio; $95 \%$ CI, 95\% confidence interval; WBC, white blood cell; PMN, polymorphonuclear leukocyte; ESR, erythrocyte sedimentation rate; SBP, spontaneous bacterial peritonitis; AKI, acute kidney injury; SIRS, systemic inflammatory response syndrome.

Table IV. Multivariate analysis by logistic regression for mortality prediction.

\begin{tabular}{lrll}
\hline Variable & OR & \multicolumn{1}{c}{$95 \% \mathrm{CI}$} & P-value \\
\hline SIRS & 103.68 & $6.57-1,633.76$ & 0.0010 \\
Fever & 18.71 & $1.42-246.06$ & 0.0258
\end{tabular}

OR, odds ratio; 95\% CI, 95\% confidence interval; SIRS, systemic inflammatory response syndrome.

between laboratory findings from ascites fluid especially leukocyte counts and the percentage of PMN and survival of patients with SBP. Therefore, the deceased patients showed increased values of these parameters compared to the patients who survived.

Our results are similar to those of Thuluvath et al in that there were no differences in the average length of hospital stay between deceased patients and those who survived (18). In contrast with their study, there was no difference in the cost of hospitalization between the two groups in the present study.

In particular, our study found that a higher proportion of SBP patients who survived were diagnosed with viral $\mathrm{C}$ cirrhosis (38.5 vs. $10 \%, \mathrm{P}=0.01)$. This association is novel, and a hypothesis could be given with the identification of new effective treatments (direct-acting antivirals) for which there is evidence that can improve the histological regression of liver cirrhosis and this improvement is associated with a better prognosis (19).

From literature data, sepsis has been shown to be one of the predictors of mortality in patients with SBP $(13,14,17,20)$. In the present study, $75 \%$ of deceased patients presented SIRS and required transfer to the intensive care unit. In addition, most patients presented with fever as an isolated symptom, in the absence of other criteria necessary to complete SIRS diagnosis, thus constituting a predictive factor of mortality.

Our study had several limitations in that it was a study that was performed in a single center, on a small number of patients and did not provide data on the prognosis of patients with SBP. In conclusion, clinical and biological parameters, previous episodes of SBP or the presence of complications were risk factors for mortality in patients with SBP. However, the presence of fever as an isolated symptom and SIRS during hospitalization were independent predictive factors of mortality.

\section{Acknowledgements}

Not applicable.

\section{Funding}

No funding was received.

\section{Availability of data and materials}

All data generated or analyzed during this study are included in this published article.

\section{Authors' contributions}

REP, CFB, AIS and APS conceived and designed the study. REP, SIM and FE acquired the data, and EP, LM, IP, FV and DOC analyzed the data. CFB, AIS, FV and SIM validated the results. EP, IP, FV, LM, FE and DOC were responsible for the preparation of the original draft. REP, CFB, EP and APS were responsible for the final manuscript editing, and REP, AIS, FV, LM and IP supervised the manuscript publication. $\mathrm{FV}$ revised and made all the corrections required for final manuscript publication. All authors read and approved the final manuscript. 


\section{Ethics approval and consent to participate}

The current study was approved by the Emergency Clinical Hospital St Apostle Andrew Constanta Ethics Committee, number 27/01.10.2020. Although not mandatory for observational, non-interventional studies at the Emergency Clinical Hospital St. Apostle Andrew from Constanta, a university hospital, all admitted patients signed informed consent by which they agreed that their data be available for academic and scientific purposes.

\section{Patient consent for publication}

Not applicable.

\section{Competing interests}

The authors of this study declare that they have no competing interests.

\section{References}

1. La Vecchia C, Levi F, Lucchini F, Franceschi S and Negri E: Worldwide patterns and trends in mortality from liver cirrhosis, 1955 to 1990. Ann Epidemiol 4: 480-486, 1994.

2. Bosetti C, Levi F, Lucchini F, Witold AZ, Negri E and La Vecchia C: Worldwide mortality from cirrhosis: An update to 2002. J Hepatol 46: 827-839, 2007.

3. Pimpin L, Cortez-Pinto H, Negro F, Corbould E, Lazarus JV, Webber L and Sheron N; EASL HEPAHEALTH Steering Committeey: Burden of liver disease in Europe: Epidemiology and analysis of risk factors to identify prevention policies. J Hepatol 69: 718-735, 2018.

4. Garcia-Tsao G: Current management of the complications of cirrhosis and portal hypertension: Variceal hemorrhage, ascites, and spontaneous bacterial peritonitis. Gastroenterology 120 726-748, 2001

5. Rimola A, García-Tsao G, Navasa M, Piddock LJ, Planas R, Bernard B and Inadomi JM: Diagnosis, treatment and prophylaxis of spontaneous bacterial peritonitis: A consensus document. J Hepatol 32: 142-153, 2000.

6. European Association for the Study of the Liver: EASL clinical practice guidelines on the management of ascites, spontaneous bacterial peritonitis, and hepatorenal syndrome in cirrhosis. J Hepatol 53: 397-417, 2010.

7. Tandon P and Garcia-Tsao G: Renal dysfunction is the most important independent predictor of mortality in cirrhotic patients with spontaneous bacterial peritonitis. Clin Gastroenterol Hepatol 9: 260-265, 2011.

8. Jun BG, Lee WC, Jang JY, Jang JY, Jeong SW, Kim YD, Cheon GJ, Lee YN, Kim SG, Cho YS, et al: Follow-up creatinine level is an important predictive factor of in-hospital mortality in cirrhotic patients with spontaneous bacterial peritonitis. J Korean Med Sci 33: e99, 2018.
9. Jain M, Sanglodkar U and Venkataraman J: Risk factors predicting nosocomial, healthcare-associated and communityacquired infection in spontaneous bacterial peritonitis and survival outcome. Clin Exp Hepatol 5: 133-139, 2019.

10. Mehta RL, Kellum JA, Shah SV, Molitoris BA, Ronco C, Warnock DG and Levin A; Acute Kidney Injury Network: Acute Kidney Injury Network: Report of an initiative to improve outcomes in acute kidney injury. Crit Care 11: R31, 2007.

11. Wong F, Bernardi M, Balk R, Christman B, Moreau R, Garsia-Tsao G, Patch D, Soriano G, Hoefs J and Navasa M; International Ascites Club: Sepsis in cirrhosis: Report on the 7th meeting of the International Ascites Club. Gut 54: 718-725, 2005.

12. Poca M, Alvarado E, Conceptión M, Pérez-Cameo C, Cañete N, Gich I, Romero C, Casas M, Román E, Castells L, et al: P0190: Predictive model of mortality in cirrhotic patients with high risk spontaneous bacterial peritonitis. J Hepatol 62 (Suppl 2): S375, 2015.

13. Niu B, Kim B, Limketkai BN, Sun J,Li Z, Woreta T and Chen PH: Mortality from spontaneous bacterial peritonitis among hospitalized patients in the USA. Dig Dis Sci 63: 1327-1333, 2018.

14. Bal CK, Daman R and Bhatia V: Predictors of fifty days in-hospital mortality in decompensated cirrhosis patients with spontaneous bacterial peritonitis. World J Hepatol 8: 566-572, 2016.

15. Alexopoulou A, Papadopoulos N, Eliopoulos DG, Alexaki A, Tsiriga A, Toutouza M and Pectasides D: Increasing frequency of gram-positive cocci and gram-negative multidrug-resistant bacteria in spontaneous bacterial peritonitis. Liver Int 33: 975-81, 2013.

16. Campillo B, Richardet JP, Kheo T and Dupeyron C: Nosocomial spontaneous bacterial peritonitis and bacteremia in cirrhotic patients: Impact of isolate type on prognosis and characteristics of infection. Clin Infect Dis 35: 1-10, 2002.

17. Tsung PC, Ryu SH, Cha IH, Cho HW, Kim JN, Kim YS and Moon JS: Predictive factors that influence the survival rates in liver cirrhosis patients with spontaneous bacterial peritonitis. Clin Mol Hepatol 19: 131-139, 2013.

18. Thuluvath PJ, Morss S and Thompson R: Spontaneous bacterial peritonitis-in-hospital mortality, predictors of survival, and health care costs from 1988 to 1998. Am J Gastroenterol 96: 1232-1236, 2001.

19. Mallet V, Gilgenkrantz H, Serpaggi J, Verkarre V, VallePichard A, Fontaine $\mathrm{H}$ and Pol S: Brief communication: The relationship of regression of cirrhosis to outcome in chronic hepatitis C. Ann Intern Med 149: 399-403, 2008.

20. Rodrigues-Pinto E and Freitas-Silva M: Hepatorenal syndrome, septic shock and renal failure as mortality predictors in patients with spontaneous bacterial peritonitis. GE Jornal Português de Gastrenterologia 19: 278-283, 2012.

his work is licensed under a Creative Commons Attribution-NonCommercial-NoDerivatives 4.0 International (CC BY-NC-ND 4.0) License. 